\title{
İran Dış Politikasında Söylem ile Eylem Uyumsuzluğu: Çeçenistan ve Dağlık Karabağ Örnekleri
}

\author{
Ridvan Kalayc1*
}

\section{Öz}

İran dış politikası, birçok dinamik tarafından etkilense de, genel çerçevesi 1979 İslam Devrimi'yle birlikte Humeyni tarafından çizilmiştir. Cumhurbaşkanları ya da Dini Lider değişse de, Şii mezhebine dayanan siyasal düzen anlayışı varlığını korumaktadır. Bu çalışmada, Humeyni sonrasında uygulanan dış politikanın, Devrimin ardından dolaşıma sokulan söylem ile örtüşüp örtüşmediği siyasal kültür-dış politika ilişkisi bağlamında tartışılmaktadır. Buradaki temel argüman, Devrimle birlikte inşa edilen Şii İslamcı siyasal düzenin temel paradigmalarının aynı kaldığı, ancak sistemsel ve siyasal değişikliklerden dolayı İranlı karar vericilerin, ulusal çıkarları ideolojik ya da kültürel çıkarlardan daha fazla dikkate aldığıdır. Bu iddiayı somutlaştırmak adına, Humeyni'nin ardından iktidara gelen Rafsancani ve Hatemi dönemlerinde cereyan eden Çeçenistan ve Dağlık Karabağ savaşları sırasındaki İran'ın uyguladığı politikalar analiz edilecektir.

Anahtar Kelimeler: İslam Devrimi, Şiilik, İran, Dış Politika, Çeçenistan, Dağlık Karabă̆

Dr., Sakarya Üniversitesi, Uluslararası İlişkiler Bölümü, rkalayci@sakarya.edu.tr, ORCID: / 0000-0002-7569-4583 


\title{
Inconsistency between Discourse and Action in Iran's Foreign Policy: Examples of Chechenia and Nagorno Karabakh
}

\author{
Ridvan Kalayc1*
}

\begin{abstract}
Although Iran's foreign policy is influenced by numerous factors, its general framework was set by Khomeini after the 1979 Islamic Revolution. Even though the Presidents or the Religious Leader have changed, the conception of the political order based on the Shia remains. In this study, in the light of political culture-foreign policy relations it is discussed whether the foreign policy applied after Khomeini coincided with the discourse that was put into circulation after the Revolution. The main argument here is that the main paradigms of the Shia Islamist political order built with the Revolution remained the same, but because of systemic and political changes, the Iranian decision-makers considered national interests more than ideological or cultural interests. In order to embody this claim, the policies of Iran during the Chechen and Nagorno-Karabakh wars that took place during the Rafsanjani and Khatami rulership will be elaborated.
\end{abstract}

Keywords: Islamic Revolution, Shia, Iran, Foreign Policy, Chechenia, Nagorno Karabakh

PhD, Sakarya University, Department of International Relations, rkalayci@sakarya. edu.tr, ORCID: / 0000-0002-7569-4583 


\section{Giriș ${ }^{1}$}

Humeyni'ye göre, Müslümanların hepsi tek bir millettir, yani "Ümmettir". Ülkeler arasında çizilen sınırlar ise emperyalistler ve baskın güçler tarafından çizilen sınırlardır. Tüm İslam ümmeti bir olmalıdır. Bütün Müslümanlar bir araya gelmeli ve bu düzene karşı meydan okumalıdır. 198088 İran-Irak Savaşı'nın ardından Humeyni, ABD başta olmak üzere Batılı ülkelerin Irak'a destek verdiğini dile getirerek “bu savaş, Kudüs'e kadar sürdürülmelidir; Kudüs yolu Kerbela'dan geçer” demiştir. ${ }^{2}$

İran’a göre 1994-96 ve 1999-2009 yılları arasında nüfusun çoğunluğunu Ortodoks Hıristiyanların oluşturduğu Rusya ile Sünni Müslümanların çoğunlukta olduğu Çeçenistan arasında yaşanan savaş, Rusya'nın bir iç meselesidir. Ortodoks Ermenistan ile Şii Müslümanların çoğunlukta olduğu Azerbaycan arasındaki Dağlık Karabağ savaşında da, İran Ermenistan'a gıda, yakıt ve lojistik başta olmak üzere askeri ve ekonomik destek vermiştir. $^{3}$

1979 devrimi sonrasında İran'1n, "ideoloji” ile "reelpolitik" arasında gelgitler yaşadığ 1 ve İranlı karar vericilerin bu ikilem arasında hareket ettiğ $i$ ifade edilebilir. Ancak Devrimin ardından yaşanan süreçte söz konusu iki

$\mathrm{Bu}$ çalışma Yazarın "Sistem Modelleri Bağlamında Devletlerin Karar Verme Süreçlerinin Karşılaştırmalı Analizi: İran, Suudi Arabistan, Mısır ve Türkiye” isimli doktora tezinden üretilmiştir.

2 May Darwich, "The Ontological (In)security of Similarity: Wahhabism Versus Islamism in Saudi Foreign Policy", Institute of Middle East Studies, GIGA Work Papers, No. 263, (2014):14

3 Thowhidul Islam, "The Nuclearization of Iran and the Policy of Russia", Asian and African Studies 22, Say1. 2, (2013): 266; Brenda Shaffer, “"'The Islamic Republic of Iran: Is It Really?", içinde The Limits of Culture, Islam and Foreign Policy Brenda Shaffer (Ed.), (Cambridge: The MIT Press, 2003): 227; Brenda Shaffer, "Iran's Role in the South Caucasus and Caspian Region: Diverging Views of the U.S. and Europe, içinde Iran and Its Neighbors: Diverging Views on a Strategic Region, Eugene Whitlock (Ed.). (Berlin: SWP, July 2003): 18-19; Soner Çağaptay, ve Alexander Murinson, Good Relations between Azerbaijan and Israel: A Model for Other Muslim States in Eurasia? (Washington: The Washington Institute for Near East Policy Press, 2005); Emil Suleymanov, ve Ondrej Ditrych. "Iran and Azerbaijan: A Contested Neighborhood", Middle East Policy 14, Say1 2, (2007): 101-116; Geoffrey Gresh, "Coddling the Caucasus: Iran's Strategic Relationship with Azerbaijan and Armenia", Caucasian Review of International Affairs 1-(Winter 2006); Claude Monmiquet ve William Racimora, "The Armenia-Iran Relationship, Strategic Implication for Security in the South Caucasus Region", European Strategic Intelligence \& Security Center, (17 January 2013):15-16. 
unsura ilişkin söylemler ile eylemler arasındaki makasın daha fazla açıldığını belirtmek gerekir. Yukarıdaki örneklere bakıldığında da, 1979 İslam Devrimi'nden sonra iç ve dış politikasını (Şii) İslam inancı esasları üzerine oluşturan İran'ın, birçok örnekte olduğu gibi bu anlayışı sahada uygulama firsatı bulduğu dönemlerde, söz konusu yaklaşımın tersine hareket ettiğ $i$ görülmektedir. Burada akla gelen ilk soru, neden İran'ın böylesi bir ikilem yaşadığıdır. Diğer bir ifadeyle İran'1, temellerini Humeyni'nin çizdiği siyasal kültür anlayışının aksine bir dış politika izlemeye sevk eden sebepler nelerdir?

Breuning'in belirttiği üzere karar vericiler üzerinde yol gösterici ya da k1sıtlayıcı bir etki bırakabilen siyasal kültür, karar vericinin mevcut politikalarını devam ettirmesini teşvik eder ya da herhangi bir kararı almasını ve uygulamasını engeller. ${ }^{4} \mathrm{Bu}$ çerçevede ulusal çıkarların tanımlanmasında da etkili olabilir. Muller ve Seligson da, siyasi elitlerin ülkedeki rejimi etkilemek için halktan daha fazla firsata ve güce sahip olması durumunda, siyasal kültür üzerinde özel bir etkiye sahip olabileceğini belirtir. ${ }^{5}$ Higley ve Burton (1989: 17-32) bu görüşe daha güçlü bir destek vererek rejimlerin istikrarının tek belirleyici unsurunun, elitler arasındaki uyum olduğunu ileri sürmektedir. ${ }^{6}$ Dolayısıyla siyasi elitler bu güce sadece sahip olmuyorlar, aynı zamanda bu gücü kullanarak siyasal kültüre ve dış politikaya yön verebiliyorlar.

Buradan hareketle İranlı karar vericiler tarafından kuruluş yıllarında riayet edilen söz konusu retoriklerin, özellikle Soğuk Savaş sonrasında pratiğe dönüşemediği görülmektedir. Tam da bu noktada, söylem ile eylem arasında neden böylesi bir uyumsuzluk olduğu araştırma sorusuna cevap bulmak adına elinizdeki çalışma, öncelikle İran'ın siyasal kültür anlayışı ile ana başlıkta adı geçen örnekler arasındaki ilişkiyi ortaya koymayı hedeflemektedir.

Bu bağlamda öncelikle İran'daki hakim siyasal kültürün temel unsurları ele alındıktan sonra İran'ın, Çeçenistan ve Dağlık Karabağ Savaşları sıra-

Marijke Breuning, Foreign Policy Analysis: A Comparative Introduction, (Palgrave Macmillan, New York, 2007).

5 Edward Muller and Mitchell Seligson, "Civil Culture and Democracy: The Question of Causal Relationships”, American Political Science Review 88, (1994): 635-652.

6 John Higley and Michael Burton 'The Elite Variable in Democratic Transitions and Breakdowns. 'American Sociological Review 54, (1989): 17-32. 
sındaki dış politikası dikkatlere sunulacaktır. Akabinde İran'ın izlediği dış politikanın, Humeyni’nin sınırlarını çizdiği siyasal kültür anlayışıyla ne derece bağdaştığına dair bulgular/tespitler ortaya konulacaktır.

\section{2. Şii İslamcı Siyasal Kültür}

Tarihin akış1 içerisinde her döneminde siyasal iktidar, hükmetme ve ülkeyi yönetme yetkisini meşrulaştırmak için belli bir kaynağa dayanma ihtiyacı hissetmiştir. Çünkü böylesi bir meşruiyet kaynağı bulunmaması durumunda tebaanın, yönetenlerin isteklerine ve iradesine uygun şekilde hareket etmesinin bir gerekçesi kalmayacaktır. Bu kaynak, yüzyıllar boyunca din olagelmiştir. ${ }^{7}$ Ayetullah Humeyni liderliğindeki İran da, temellerini (Şii) İslam inancı üzerine inşa etmiş, iç ve dış politikasını da bu gerçeklik üzerine oluşturmaya çalışmıştır. Bu bağlamda 13. yüzyıl Şii geçmişinden ve geleneklerinden gelen İslami siyasal kültür, din adamlarının başını çektiği farklı muhalif toplumsal grupların, hayal kırıklıklarını gösterebilmek için alternatif ideolojiler araması üzerine ön plana çıkmaya başlamıştır. ${ }^{8}$ İslamc1lara göre, kendilerinden önceki siyasal hareketlerin başarısız olmasının temel sebebi, halka mücadele azmi verecek bir öğretiden uzak olmalarıdır. Humeyni liderliğinde gerçekleştirilen Devrimle birlikte, insanların zihinlerine ve yaşamlarına 'Velayet-i Fakih' anlayışına dayalı bir İslami Hükümet düşüncesi yerleştirilmiştir.' $\mathrm{Bu}$ anlayışa göre siyasi örgütlenmenin amac1, insanın Şer-i hükümlere göre yaşamasının ve en sonunda Allah'a ulaşmasının sağlanmasıdır. Bundan dolayı Anayasal düzenlemeler, İslami yönetimi güçlendirmeye yönelik olmalı, uygulamalar Kur'an ve Sünnet çerçevesinde hayata geçirilmelidir. ${ }^{10}$ Dini liderlere göre, Kuran'1 Kerim'de Allah'ın,

Enes Sanal, "Demokrasi Kavramı Açısından Devlet ve Din İlişkileri”, Başkent Üniversitesi Stratejik Araştırmalar Merkezi, (Ankara, 2014):4-5; Mario Ferrero, "The Rise and Demise of Theocracy: Theory and Some Evidence, "Religion and Democracy" in the annual conference of the Association for Public Economic Theory", (Galway, June 17-20, 2009): 2.

8 Samih K. Farsoun ve Mehrdad Mashayekhi, "Introduction: Iran's Political Culture", içinde Iran, Political Culture in the Islamic Republic, Samih K. Farsoun and Mehrdad Mashayekhi (Ed.), (Routledge, 1993), s. 6.

9 “İran İslam Cumhuriyeti'nde Anayasal Sistem ve Siyasi Partiler, Orsam Rapor, no. 112, (Mart 2012), s. 6.

10 Bayram Sinkaya, "İran İslam Cumhuriyeti'nde Siyasal Yapı ve Yönetim”, içinde Ortadoğu Siyasetinde Iran, Turel Yılmaz ve Mehmet Şahin (Ed.), (Ankara: Barış Kitabevi, 2011): 19. 
İmam'1 günahlardan koruduğu, bu nedenle ari/saf bir insan olan İmam'ın, yasa yapmakta tam yetkili olduğu kabul edilmektedir. Yani İmam'ın aldığı kararlar kesindir, karşı gelinemez ve Şeriatın vazgeçilemez bir parçasıdır. ${ }^{11}$ $\mathrm{Bu}$ anlamda Monarşik siyasal kültürle benzerlik arz etmektedir. Zira her iki kültürde de, hiyerarşinin en tepesindeki ismin aldığ 1 kararların meşrulaştırılması için bir "araç" kullanılması söz konusudur. Humeyni döneminde bu rolü "İslam (Şiilik)" oynarken, Şah dönemlerinde ise "batıc1lk" ve "milliyetçilik" oynamıştır.

Genel çerçevesi Humeyni tarafından çizilen İslami siyasal kültürün temel paradigması ise, kayıp İmam'ın geri dönüşüne kadar kutsal yasanın hükümleri doğrultusunda yönetme erkinin ehil hukukçulara düştüğü, bundan dolayı Kur'an'ın yorumlayıcıları olarak Dini Liderlerin yönetme hakkına sahip olduğudur. ${ }^{12}$ Tam da bu noktada mevcut yaklaşım, Pehlevi dönemindeki Monarşik siyasal kültürden farklılaşmaktadır. Çünkü karar verici siyasi elitler tarafından inşa edilen Monarşik yapıda ulema sınıfı, etkinliği azaltılması gereken ve Batılılaşma ile modernleşmenin önünde bir engel olarak görülmektedir. İslamcı siyasal kültürde ise, devleti yönetmeyi hak eden kesim olarak öne çıkmaktadır. Humeyni'ye göre İslami hükümet, anayasal bir yönetimdir. Ancak buradaki anayasa, hukukçular tarafindan oluşturulan yasa değil, Kur'an'da ve Peygamber'in sünnetinde ortaya konulan İslami emir ve yasalardır. Bu yasaları doğru şekilde uygulayabilecek olan tek kesim din adamları olduğu için, yönetme yetkisi de doğal olarak onların sorumluluğundadır. ${ }^{13}$

Humeyni'ye göre, Müslümanların hepsi tek bir millettir, yani “Ümmettir". Ancak ülkeler arasında çizilen sınırlar ise emperyalistler, baskın güçler tarafindan çizilen sınırlardır. Bundan dolayı bütün Müslümanlar bir araya gelmeli ve bu düzene karşı meydan okumalıdır. ${ }^{14}$ Ancak burada altının çizilmesi gereken nokta, Humeyni yönetiminin İslam vurgusunun altında esasen Şii İslam anlayışının olduğudur. Aksi halde Humeyni yönetimi, devrim sonrasında Arap ülkelerindeki Monarşilerin yıkılması yönünde bir tavır takınmazdı. Bunun yanında söz konusu Pan-İslamist söylemler, Fi-

\footnotetext{
11 Ercan Çitlioğlu, İran'1 Anlamak, (Başkent Üniversitesi, 2015): 17.

12 Hamid Algar (Ed.), Islam and Revolution: Writings and Declarations of Imam Khomeini, (Berkeley: Mizan Press, 1981): 47-49.

13 Algar, Islam and Revolution: Writings ..., 55, 78.

14 Darwich, "The Ontological (In)security of Similarity: Wahhabism Versus Islamism, 14.
} 
listin sorununda aktif bir destek şeklinde ortaya konulmuş, aynı zamanda Hamas, Filistin İslami Cihat ve Hizbullah örgütlerine destek verilmesi, Müslümanların birlikte hareket etmesinin ve İran'ın buna öncülük yapmasının bir göstergesi olarak görülmüştür.

\section{3. Şii İslamcı Siyasal Kültürün Temel Unsurları:}

\subsection{Milliyetçilik}

Çok köklü bir geçmişe sahip olan İran'ın devlet yapısında, İslam öncesi imparatorluklardan kalma izler görülmektedir. Ahameniş İmparatorluğu'nda tam olarak görülen ve seri işleyen bir idari yapı, güçlü ordu ile düzenli ve sıkı bir kontrol mekanizması, Pehlevi dönemine ve sonrasında İslam Cumhuriyeti'ne kadar varlığını devam ettirmiştir. ${ }^{15}$ İran milliyetçiliği de, en genel anlamda, çok geniş bir coğrafyada hakimiyet kuran Pers İmparatorluğu'na dayanmaktadır. Yayılmacı ve nüfuz etmeye yönelik politik tavır da, büyük oranda bu geçmiş ile ilişkilendirilmektedir. ${ }^{16}$ Kendisinden önceki imparatorluklar gibi çok etnikli bir yapı arz etmesinden dolayı İran, etnik aidiyetten ziyade bir üst kimlik üzerinden milliyetçilik tesis etmeye çalışmıştır. İran milliyetçiliğinin diğer bir dayanak noktası ise tarih boyunca, birçok büyük güç tarafından (Yunan, Arap, Türk, Moğol vs.) işgal edilmiş olmasıdır. ${ }^{17} \mathrm{Bu}$ işgal sendromu, büyük güçlere karşı ihtiyatlı yaklaşılmasına ve İslam Devrimi'nden sonra da “ne Doğu, ne de Batı" politikasının uygulanmasına kaynaklık etmiştir.

Safeviler döneminde din, yani Şiilik de, milliyetçiliğin ve Sünni Arap coğrafyasından ayrışmanın önemli bir enstrümanı olarak öne çıkmış, Pehlevi döneminde ise, Pers kültürünü ve Zerdüştlük'ü anımsatan uygulamalar dolaşıma sokulmuştur. Şah döneminde bilinçli bir şekilde İran'ın diğer Arap devletlerinden farklı olduğu, dininin, dilinin ve giyim şeklinin vs. bu ülkelerle aynı olmadığ 1 vurgulanmaya çalışılmıştır. ${ }^{18}$ Milliyetçiliğin bir

15 Tahereh Ahin, “İran İslam Cumhuriyeti’nde Devlet Yapısı”, Amme İdaresi Dergisi 43, Say1. 2,(2010,) :82-83.

16 Autoosa Elizabeth Kojori Saatchi, "The Culture of Revolution: Revolutionary Transformation in Iran, University of Nevada" (2010):30.

17 Jahangir Amuzegar, The Dynamic of the Iranian Revolution, The Pahlavis' Triumph and Tragedy, (New York: State University of New York Press, 1991).

18 Saatchi, "The Culture of Revolution", 33. 
diğer düsturu ise, 1950'li yıllarda Musaddık önderliğinde başlatılan ulusal servetlerin, yani yer altı kaynaklarının yabancı güçler tarafından kullanılmasına karşı çıkılmasıdır. Fahiş fiyatlar üzerinden İran petrol sektöründe hegemonyasını kurmuş olan İngilizlere karşı başlatılan petrol sektörünün millileştirilmesi çalışmalarına yönelik, İngiltere'nin Musaddık karşıtlarını kullanması ve ayrıca ABD'yi de yanına alarak bir darbe gerçekleştirmesi, bu iki ülkeyi temel alan bir emperyalizm karşıtlığını ortaya çıkarmıştır. Daha önceleri ABD'ye olan 1lımlı yaklaşım, Darbe ve sonrasındaki yaptırım sürecinde $\mathrm{ABD}$ 'nin de yer almasından dolayı, yerini $\mathrm{ABD}$ karşıtlığııı milliyetçi düşüncelerin merkezine yerleştiren bir anlayışa bırakmıştır. ${ }^{19}$

\section{2. Şii İslam Anlayışı}

İslam dini, Arapların İran toprakların fethetmesinin ardından bu coğrafyada yayılmaya başlamıştır. Safevi Hanedanlığının, 16. Yüzyılda Şiiliği devletin resmi dini olarak kabul etmesiyle birlikte Şiilik, İran' da hakim inanış haline gelmiştir. Bu anlamda Şiilik, Safevi devletine ve sonrasında gelen Hanedanlara, Sünni devletler karşısında ideolojik bir temel oluşturmuştur. ${ }^{20}$ Dini yönüyle Şiilik, Zeydilik, İsmailiyye ve İsna'aşeriyye (Caferilik) olmak üzere üç kola ayrılmıştır. Caferiler, Hz. Muhammed'in soyundan olmak üzere Hz. Ali ile başlayan 12 İmam'a inanmaktadırlar. Ancak on ikinci imam olan Muhammed bin Hasan'ın kayıp olduğuna ve kıyamete yakın bir zaman diliminde ortaya çıkacağına dair bir görüş hakimdir. ${ }^{21}$ Caferiliğin içerisinde de, Ahbari ve Usuli kolları arasında din hukukunun uygulanması konusunda görüş ayrılıkları mevcuttur. Yaşanan uzun tartı̧̧maların ardından, "içtihat" görüşünü savunan Usuli'ler, bu mücadeleyi kazanmışlardır. Bu anlayışa göre Müçtehitler, hem İslam hukuku konusunda kendi görüşlerini bildirme yetkisi olan, hem de bu görüşlerine uyulmasının zorunlu olduğu kimselerdir. Yani herhangi bir mesele hakkında Kur'an ve Sünnet'ten yorumlar çıkartabilmektedirler. ${ }^{22}$ Ayetullah Humeyni de, "Usuli" kolundan gelmektedir.

\footnotetext{
19 Ahin, “İran İslam Cumhuriyeti'nde Devlet Yapısı”, 84

20 Hamid Algar, İslam Devrimi'nin Kökleri, çev., M. Çetin Demirhan, (İşaret Yayınları, Ankara, 1988): 17-54

21 Hasan Onat, “Şiilik ve Günümüz Şiiliğinde Bazı Yeni Yaklaşımlar”, İslami Araştırmalar 3, Say1. 3, (Temmuz 1989): 122-138.

22 Abdülbaki Gölpınarlı, Tarih Boyunca İslam Mezhepleri ve Şiilik, (Der Yayınları, İstanbul, 1997), s. 225.
} 
Pehlevi döneminde Şiiliğin devlet üzerindeki etkisi çok sınırlı kalmış, hatta İslam yerine, İslam öncesi dönemlere vurgu ön plana çıkarılmıştır. Araplara karşı etnik ulusçu yaklaşımlar belirgin hale getirilirken, İslami geçmiş ise göz ardı edilmiştir. ${ }^{23}$ Çarşafın yasaklanması, ulema sınıfının sahip olduğu ayrıcalıklı konumun ellerinden alınması ve Batılı kültürün yerleştirilmeye başlanması, Şiiliğin, Pehlevi döneminde etkisinin azalmasına neden olmuştur. Ancak 1979 İslam Devrimiyle birlikte İran'ın kültürüne esas rengini veren Şiilik, devletin resmi ideolojisi olmakla birlikte, siyasal sistemin düzenlenmesinde kıstas alınan temel parametre özelliği de kazanmıştır. Aslında Devrim esnasında ve Irak-İran Savaşı sırasında Humeyni yönetimi, Şiilikten daha çok İslam'ı ön plana çıkarmaya çalışmış, ancak özelde Şiiliği işlemeye gayret göstermiştir. Humeyni döneminin neredeyse tamamının Irak'la savaşta geçtiği göz önüne alındığında, ilk önce İslam'ın söylemlerde kullanılması daha net anlaşılmaktadır. Zira savaşta İran'ın yaptığı direniş mücadelesi, sadece kendisini savunmak için değil, aynı zamanda Irak'ın arkasında duran tüm Batılı devletlere, Arap ülkelerine ve hatta Sovyetler Birliği'ne karşı yapılmıştır. Bir manada Devrimin ortaya çıkış felsefesini oluşturan Batı karşıtlığının bu savaşla birlikte haklılığının ortaya çıkması ve İran içerisinde Şiilik ve Fars kimliği etrafında birleştirici bir özellik ortaya çıkarması, Humeyni’yi, bu savaşı, "Kudüs'e kadar sürdürülmesini” söylemeye itmiştir. "Kudüs yolu Kerbela' dan geçer” diyerek, nihai hedeflerinin İslam Devrimini, bütün Ortadoğu'ya yaymak olduğunu göstermiştir. ${ }^{24}$

\subsection{Batıcilık}

Batılılaşma olgusu, dönemler itibariyle çok farklı bakış açılarıyla ele alınmış, bir dönem "varılacak hedef" olarak gösterilirken; bir dönem de, kimlik tanımlamasının "ötekisi" olarak ifade edilmiştir. Bu anlamda Şah yönetimi, Batılılaşmayı, modernleşme ile eş anlamlı görmüştür. Ancak buradaki modernleşme olgusu, sanayileşme ve askeriyenin güçlendirilmesinden ibaret görülmekteydi. Batının silahlarını satın almak ve güçlü bir ordu kurmak, Şah yönetimi tarafından Batılılaşmanın önemli bir göstergesi

\footnotetext{
23 Edward Wastnidge, "The modalities of Iranian soft power: from cultural diplomacy to soft war", Politics 35, No. 3-4, (2015):368-369.

24 Hasan Onat, “İran İslam Devrimi ve Şî̂lik”, Mezhep Araştırmaları, (Güz.):236- 23.7
} 
olarak değerlendirilirken, bu uygulamalar, İran'1 yabancı yönetici ve satış temsilcilerinin akınına uğratmış, halkın ve orta ve küçük ölçekli işletmelerin yönetime karşı tepkisini artırmıştır. ${ }^{25}$

Batılılaşmanın Şah dönemindeki diğer çıktılarından olan Batı kültürünün halka benimsetilmeye çalışılması, Medeni Kanunun İslami yargının önüne geçirilmesi ve yargı organlarında ulema sınıfının, sarıksız insanların alt sıralarında oturtulması, dini otoritelerin konumunun ciddi bir şekilde sarsılmasına neden olmuştur. Şah'ın, “İran Rönesansı" olarak adlandırdığı bu dönemdeki uygulamaları, Batı kültürünü taklit etmesinden dolayı tepki çekmiştir. ${ }^{26}$ Ayrıca sözkonusu modernleşme çalışmaları yukarıdan aşağıya doğru ve yüzeysel olmasından dolayı geleneksel toplumsal yapıyı değiştirmede başarısız olmuş, sosyal yapı içerisindeki nüfuz alanları ve bağlantılar, varlığını korumaya devam etmiştir. ${ }^{27}$ Morteza Motahhari, Mohammad Beheshti, Morteza Jazayeri ve Mahmud Taleqani'nin başını çektiği Şii akademisyenler ve din adamları, hükümetin İslam'a uygun hareket etmesi, dini kurumların ve bağımsız finans örgütlenmelerinin oluşturulması gerektiğini ifade ederek, Batılılaşma çalışmalarına karşı çıkmışlardır. Bu fikre karşı, İslam'ın, hayatın tamamında etkin olması, gençleri etkilemesi ve onlar için hayat rehberi olması gerektiği ve toplum olarak birlikte hareket etmelerinin elzem olduğu yönündeki görüşleri ileri sürerek, Şah'ın düşüncelerinin aksini savunmuşlardır. ${ }^{28}$

1960 ve 70'li yıllarda Şah'ın, Batılılaşmayı, daha fazla Amerika yanl1s1 olmak şeklinde hayata geçirmesi, Ali Şeraiti ${ }^{29}$ ve Jalal Al-e Ahmed ${ }^{30}$

25 Alam Asghar Tabriz, “Aydınların, Dini Liderler ve Esnafin İan'in Yakın Dönem Toplumsal Hareketlerindeki ve Devrimlerindeki Rollerinin İncelenmesi, Yayınlanmamış Doktora Tezi, (Ankara: Ankara Üniversitesi, 2004):161.

26 Tabriz, “Aydinların, Dini Liderler ve Esnafin ..., 162.

27 Ahin, “İran İslam Cumhuriyeti’nde Devlet Yapısı”, 85.

28 Shahrough Akhavi, Religion and Politics in Contemporary Iran, (Albany State University of New York Press, 1980), ch. 5.

29 Eski dini konuları, mevcut dönemin şartlarına uyarlayarak ele alan Shar'iati, özellikle radikalizme yakın olan gençlere "milli benliğimizi/kimliğimizi nasıl koruyabiliriz?" ve "bu konuda neler yapılmalı?" gibi sorular sorarak, Batı karşısında kendi kimliklerini korumak için kendi İslami kültürlerine dönmeleri gerektiğini dile getirmiştir. Bkz: Forough Jahanbakhsh, Islam, Democracy And Religıous Modernism In Iran (19531997): From Bàzargan To Soroush, PhD Thesis, Institute of Islamic Studies, (McGill University, Montreal, Temmuz 1997):201-214.

30 O dönem entellektüel gençler arasında etkili olan bir diğer gelişme ise Batı kültürüne ve Batının İran içerisindeki ekonomik nüfuzuna ve etkinliğine eleştirel tavrıyla bilinen 
gibi yazarları, Batı karşıtlığı üzerinden örgütlenmeye itmiş, Ayetullah Humeyni'nin ${ }^{31}$ de bu sürece katılmasıyla, Batı karşıtllğ̆ı, Şah'a karşı gelmenin ortak noktalarından birisi haline gelmiştir. Baba ve oğul Şah dönemlerinde Batılılaşma, "modernleşme", "sanayileşme" ve "ekonomik kalkınma" ile özdeşleştirilirken, İslam Devriminden sonra "Şeytan'a yardım etme", "İslam'a karşı verilen savaşın kaynağı" ve "İran kültürünü yok eden bir zehir" olarak görülmeye başlanmıştır.

\section{Siyasal Kültürün Soğuk Savaş Sonrası Dış Politikaya Yansıması}

1991-2001 arası dönemde ABD’nin tek süper güç olarak yer aldığı uluslararası yapıda, (Şii) İslamcı siyasal kültürün hakim olduğu Teokratik Cumhuriyet rejimiyle yönetilen İran, büyük güçlerle uyumlu ve statükocu bir yaklaşım sergileyerek Şii-İslam dayanışmasına yönelik dış politika uygulamaya çalışmıştır. Burada vurgulanması gereken ilk nokta, değerlendirmeye tabi tutulan dönemin, İran'da yönetim değişikliğinin olduğu, diğer bir ifadeyle Humeyni ile karşılaştırıldığında 1lımlı kanattan gelen Rafsancani ve Hatemi'nin Cumhurbaşkanı olarak iktidara geldiği bir zaman dilimine denk geldiğidir. Bu zaman dilimi içerisinde ABD'nin uluslararası sistemdeki hegemonik pozisyonu devam etmekle birlikte bölgesel alt sistemde Irak'ın Kuveyt'i işgal etmesine binaen istikrarsızlığın olduğu ve bölgesel dengelerin değiştiği bir ortam mevcuttur. Siyasal kültür açısından bakıld1-

yazar Jalal Al-e Ahmad'in, Gharbzadegi (Westoxication) ismiyle çıkardığı kitaptır. Ahmad, Batının kötü yönleriyle bir toplumu zehirlediğini işlediği kitabıyla, halkı, özellikle de gençleri buna karşı çıkmaya davet etmiştir. Bkz: AK Ramakrishnan, The Making of A Revolution I: Religious Political Discourse, Chapter 3, (2010):110-133.

31 Ayetullah Humeyni, 1943 yılında 'Esrarın Keşfi/Kashf Al-Asrar isimli yazdığı kitapta 1940'l1 yıllarda Şah tarafindan uygulanmakta olan politikalara eleştiriler getirirken, halkın İslam'dan uzaklaştırılarak Batı kültürüne yakınlaştırıldığını belirtmekteydi. Özellikle Şah'ın “Ak Devrim” adıyla gerçekleştirmeye çalıştığı reformların "şeytan Amerika" ve müttefikleri tarafından uygulatıldığını dile getirerek hem Şah’a karşı ilk ciddi tepkisini verecek, hem de ABD'yi ve Batılı müttefiklerini “öteki” konumuna yerleştirecektir. Bkz: M.Serkan Taflığlu, Şah Nasil Mat Oldu, (Kripto Yayınları, 2010): 116-121. Ayrıca 1971 yılında, o dönemki gençliği Devrime hazırlamayı hedeflediği, ülkeyi bir İslam Devleti'ne dönüştürecek olan idealleri ele aldığı Houkumat-e İslami/ İslam Hükümeti(İslam Fıkhında Devlet) isimli kitabında, İran'da niçin bir İslam rejimine ihtiyaç duyulduğunu anlatmaya çalışmıştır. Bkz: M. Serkan Taflıŏlu, İran İslam Cumhuriyeti'nde Egemenlik ve Meşrûiyet Kaynağı "Velâyet-İ Fakih" Ankara Üniversitesi SBF Dergisi 68, No. 3, (2013):97-100; İmam Humeynî, İslamda Devlet, (İstanbul: Objektif Yayınları 1991). 
ğında ise, Humeyni liderliğinde inşa edilen (Şii) İslamcı siyasal kültürün varlığını devam ettirdiği, ancak siyasi liderler tarafından Humeyni gibi radikal bir şekilde yorumlanmadığı ifade edilmelidir.

1991 yılında, SSCB'nin dağılmasının ardından Soğuk Savaş'ın sona ermesi, küresel sistemde diğer devletlerce dengelenmesi mümkün olmayan ABD'nin, tek süper güç olduğu gerçeğini ve genellikle tek kutupluluk olarak tanımlanan bir yapıyı ortaya çıkarmıştır. Krauthammer'in de belirttiği üzere, ABD'yi ekonomik olarak dengelemenin ya da karşısına ekonomik bir güç çıkarmanın, onun mevcut uluslararası sistemdeki hakim konumunu tam anlamıyla dengelemek anlamına gelmediğini belirtmek gerekmektedir. ${ }^{32}$ Buradan hareketle, ABD'nin liderliğindeki tek kutuplu bir düzende, onunla çatışarak, onu göz ardı ederek ya da doğrudan karşısına alarak bir dış politika geliştirmek, sürdürülebilir ve rasyonel bir yaklaşım olmamaktadır. Özellikle ulusal güç kapasitesi itibariyle ABD'den çok daha güçsüz konumda bulunan ve ABD'nin yaptırımlarına maruz kalan orta büyüklükteki bir devletin (İran gibi) böylesi bir dış politika tavrı sergilemesi beklenmemelidir.

Bu yargıyla birlikte, İran rejiminin yanı sıra hükümet yapısı ve karar vericilerini de dikkate alarak bir değerlendirme daha yapmak gerekir. Zira 1979 yılında uluslararası sistemde herhangi bir değişiklik yokken rejim değişmişti ve buna bağlı olarak diş politikada keskin farklılıklar görülmüştü. Şimdi ise, rejimsel ve siyasal kültürde herhangi bir değişiklik olmamasına karşılık, sistemsel düzeyde gerçekleşen değişiklikten dolayı, Rafsancani hükümeti, oluşan yeni şartları dikkate alarak farklı bir dış politika anlayışını benimsemek zorunda kalmıştır. Sınırlarını Humeyni'nin çizdiği ideolojik yapı varlığını aynen korurken ve yeni Dini Lider Hamaney de benzer görüşleri savunurken, iktidarda bulunan Hükümet, "rejim ihracından", "kendi içerisinde İslam"33 politikasına geçerek siyasi zihniyeti, uluslararası sistemin tek kutupluluğa dönüşmesi bağlamında değerlendirdiğini göstermiştir. Bu bağlamda Humeyni’nin inşa ettiği (Şii) İslamcı siyasal kültürde “büyük şeytan” şeklinde tanımlanan ABD, Hatemi'nin, büyükelçilik bas-

32 Charles Krauthammer, ““"The Unipolar Movement Revisited”, The National Interest 3 , Winter 2002, s. 25-26.

33 Abdullah Yeğin, "Devrim'in 35. Yılında İran Dış Politikası", SETA Perspektif, Sayı. 32, (2014): 2-3. 
kınıyla ilgili yaptı̆̆ konuşmada "büyük Amerikan halkı" ifadesiyle kendisine yer bulmuştur. ${ }^{34}$

Bunun yanında İran'ın tek başına ABD'yi durdurabilecek ulusal imkanlara sahip olmadığı da bir gerçektir. Bu nedenle ABD'nin baskılarını hafifletecek ya da dengeleyecek adımlar atmaya çalışmıştır. Bunu da iki yolla gerçekleştirmeye gayret etmiştir. Birincisi ABD karşısında daha zayıf aktörler olarak öne çıksa da, güç parametreleri ışı̆̆ında büyük güçler arasında yer alan Çin ve Rusya gibi devletlerle ilişkilerini derinleştirme ve işbirliğini geliştirme girişimleridir. İkincisi ise, ABD ile gerginliğin düşürülmesini sağlayacak adımların atılmasıdır. Bunun ilk adımı 1991 yılında Irak'ın, Kuveyt'i işgali üzerine $\mathrm{ABD}$ öncülüğünde başlatılan operasyona karşı çımayarak atılmıştır. Ancak buradaki tek öncelik ABD'yle gerginliğin düşürülmesi değildir. Zira bundan daha da önemlisi İran, bölgesel statükonun bozulmasını istememiştir.

Ancak Humeyni'nin sınırlarını çizdiği ideolojik yaklaşım, revizyonist argümanlarıyla öne çıkmaktaydı. Ayrıca yakın coğrafyasındaki Monarşilerin yıkılmasını ve Şii İslam'ın tüm Ortadoğu bölgesine yayılmasını hedeflemekteydi. Bu bağlamda Kuveyt'in işgaliyle Sünni Müslümanların çoğunluğunu oluşturduğu bir ülkedeki Monarşi’nin yıkılması söz konusuydu. Fakat Tahran yönetimi bu değişikliğe karşı çıkarak, retorikteki revizyonist hedeflerin aksi yönünde bir uygulamayı pratiğe dönüştürmüştür. Dolay1sıyla Şii-İslamcı siyasal kültürün, İran dış politikasında ve karar vericileri üzerinde bir etkisinin olduğunu söylemekle birlikte, bu örnekte olduğu üzere dış politikanın ana belirleyici unsuru olmadığını da vurgulamak gerekmektedir.

\section{1. Çeçenistan Savaşları}

İran anayasasında bütün Müslümanlara kardeşçe yaklaşılması ve tüm ezilen Müslümanlara destek verilmesi gerektiği belirtilir. Ancak İran'ın bu ideali gerçekleştirme adına seçici davrandığı ifade edilebilir. Çeçenistan Savaşına yönelik İran'ın resmi olarak gösterdiği reaksiyon, diğer İslam

34 Patrick Clawson, "The Khatami Paradox”, Patrick Clawson et. al. , (Eds.), Iran Under Khatamı A Political, Economic, And Military Assessment, (The Washington Institute For Neear East Policy, 1998): 4-5. 
devletleri, uluslararası kuruluşlar ya da dini örgütlenmelerin tepkileriyle karşılaştırıldı̆̆ında daha net bir şekilde anlaşılabilir. Zira İran'ın dış politikasında ifade edilen ve tüm Müslümanları kapsayan/kuşatan söylemler ile İslam'1 yayma ve Müslüman ülkelerle dayanışma içerisinde olunmas1 gerektiği yönündeki retorik yaklaşımlar, 1994-96 ve 1999-2009 yılları arasında Rusya ile Çeçenistan arasında yaşanan savaş esnasında bir türlü pratiğe dönüş(e)memiştir. Oysaki Çeçenler, İslami hedefleri olan ve hükümetleri tarafından Şeriat kanunlarının kabul edildiği bir toplum olarak öne çıkmaktayd1. ${ }^{35}$ Ancak İran, onları, ABD'den ve Suudi Arabistan'dan silah desteği alan Sünni radikal gruplar olarak görüyordu. Özellikle birinci Çeçenistan savaşıyla (1994-1996) ilgili İran yönetiminin açıklamaları, ABD veya $A B$ 'nin açıklamalarından daha yumuşak bir dil içeriyordu. Ayrıca Rusya'nın toprak bütünlügüne saygı duyulması gerektiği ve Çeçen meselesinin Rusya'nın bir iç sorunu olduğu da belirtiliyordu. ${ }^{36}$

Bu bağlamda Rus Hava Kuvvetleri'nin Çeçenistan'ın başkenti Grozni'yi bombalamaya başlamasının ardından kara birliklerinin de 30 Eylül 1999 tarihinde Çeçenistan'a girmesi üzerine İran Dışişleri Bakanı Kemal Karrazi, Rus mevkidaşı Igor Ivanov'a gönderdiği mesajda bu mücadelenin Rusya'nın bir iç meselesi olduğunu söylemiştir. Karrazi ayrıca, Rusya'nın istikrarını bozan teröristlere karşı mücadelede etkili işbirliği yapabileceklerini de iletmiş̧ir. ${ }^{37}$ Rusya Dışişleri Bakanlığ tarafindan yapılan açıklamada ise, İran'ın Çeçen sorunundaki itidalli ve dengeli yaklaşımının olumlu karşılandığg ifade edilmiştir. ${ }^{38}$

Diğer taraftan Rusya'da yaklaşık olarak 20 milyon Müslüman'ın yaşıor olması, Moskova yönetimini İslam dünyasının mevcut soruna bakışının kendi görüşlerine yakın olması için çaba sarf etmeye itmiştir. Birinci Çeçenistan savaşının devam ettiği bir süreçte Aralık 1994'te Kazablanka'da toplanan İKÖ, Çeçenistan sorununa sadece bir cümle ayırmıştır. O vurguda ise, Çeçenistan'da son dönemde yaşanan gelişmelerden derin endişe duyulduğunu, Rusya'nın toprak bütünlüğünü dikkate alarak tarafların daha fazla kan dökülmeden soruna barışçıl bir çözüm bulmaları gerektiği

\footnotetext{
35 Shaffer, “The Islamic Republic of Iran: Is It Really?”, s. 227.

36 Shaffer, “The Islamic Republic of Iran: Is It Really?”, s. 228.

37 "Iran Report”, RFE/RL 2, No. 39, (4 October 1999).

38 A. William Samii, "Iran and Chechenya: Realpolitik at Work", Middle EAst Policy Council VIII, Say1. 1, (Spring 2001).
} 
ifade edilmiştir. ${ }^{39}$ İkinci Çeçenistan savaşının başlangıcında ise İran, İKÖ başkanlığg görevini yürütmekteydi ve örgütün Rusya karşıtı bir pozisyon almamasına da ön ayak olduğu belirtilmektedir. Hatta İran'ın İKÖ'deki rolüne dair Rusya Federasyon Konseyi/Meclis Başkanı Sergey Mironov, Tahran yönetimine teşekkür etmiştir.

Daha sonra İKÖ tarafindan yapılan açıklamalarda da itidalli bir dil kullanılmaya devam etmiştir. "Endişe", "büyük endişe", "Rusya'nın toprak bütünlüğ̈̈" ve "iç işlere müdahale etmeme" gibi kelimelerin tercih edilmesi de bu yargiyı desteklemektedir. ${ }^{40}$ Zira gerek İKÖ tarafından Rusya'ya gönderilen delegasyon, gerekse Karrazi'nin açıklamaları, İran'ın mevcut sorunun insani boyutunu öne çıkardığını ve bu alanda yardımda bulunmaya hazır olduğunu göstermektedir. Ancak söz konusu savaşın siyasi boyutuna ilişkin Karrazi, Çeçenistan sorununun Rusya'nın toprak bütünlüğüyle alakalı bir konu olduğunu ve bunun da Rusya'nın bir iç meselesi olduğunu tekrar dile getirmiştir. Ayrıca iki ülke arasındaki yakınlaşmaya binaen Kemal Karrazi, Rusya ile Çeçenistan arasında arabulucu olabileceklerini söylese de, bu teklif Rusya tarafından kabul edilmemiştir. ${ }^{41}$

Bunların yanında şu da ifade edilmelidir ki, birinci Çeçenistan savaşında Rusya yanlısı gösterilen tutum, 1999 yılında başlayan ikinci Çeçenistan savaşında çok net ortaya konulamamıştır. Zira Rus askerlerinin Çeçenistanlı sivilleri katlettiklerine ilişkin raporların çıkması ve görüntülerin medyada yayınlanması İran'ı ikilemde bırakmıştır. Bir yanda Rusya'yla olan mali ve askeri çıkarları varken, diğer yanda Müslümanların öldürülmesine karşı İKÖ’nün dönem başkanı ve Müslüman bir devlet olarak tepki göstermesine yönelik beklentiler söz konusudur. Ancak İran, söz konusu ikilem karşısında insani konuları gündeme getirmeyi tercih ederken, Rusya karşıtı bir pozisyon almaktan da imtina etmiştir. Örneğin İran Dışişleri Bakanı Karrazi, Rus mevkidaşı Grigori Karasin'e, Çeçenistan savaşının devam etmesinin İslam dünyası açısından kabul edilemez olduğunu ve İslam dün-

\footnotetext{
39 TheSeventhIslamic SummitConference(SessionofFraternity andRevival). Casablanca, Kingdom Of Morocco, 11-13 Rajab 1415h (13-15 December, 1994), http://www.oic-oci. org/english/conf/is/7/7th-is-summit.htm\#FINAL\%20COMMUNIQUE (accessed 25 February 2007)

40 "Iran Report", RFE/RL 3, No. 12, (20 March 2000).

41 “Iran Report", RFE/RL 3, No. 12, (20 March 2000).
} 
yasında Rusya'nın imajına zarar vereceğini ifade etmiştir. ${ }^{42}$ Fakat bu açıklamalar iki ülke arasındaki resmi ilişkilerin seyrinde herhangi bir olumsuz netice otaya çıkarmamıştır. Nitekim Sergey Mironov, 2004 yılında İran Meclisinde yaptığı konuşmada, Tahran yönetiminin Çeçenistan sorunundaki tutumundan ve Rusya'nın toprak bütünlüğüne göstermiş olduğu saygıdan dolayı mutluluk duyduğunu söylemiştir. ${ }^{43}$ İran'ın Çeçen sorununa ilişkin resmi reflekslerine dair çarpıcı bir örnek vermek gerekirse; 2005 ve 2006 yıllarında Danimarka' daki bir gazetede Peygamber efendimiz hazreti Muhammet (SAV)'e ilişkin karikatürlerin yayınlanmasına İran rejiminin göstermiş olduğu reaksiyonun, Çeçenistan savaşına karşı verdiği tepkiden çok daha fazla ve sert olduğunu söylemek mümkündür.

Çeçenlerin çoğunun Sünni olması dikkate alındığında İran'ın mevcut yaklaşımını, Humeyni'nin, Şii İslam'1 yayma anlayışı içerisinde değerlendirmek ve bölgedeki Sünni İslam'ın etkinliğini artırmasının engellenmek istendiği şeklinde bir yargıya varmak mümkündür. Ancak Tahran yönetiminin tepkileri, İran kamuoyunun veya medyasının da Çeçenistan konusundaki yaklaşımlarını yansıttığı söylenemez. Çünkü İran'ın uluslararası toplum tarafından baskı altına alınmış olması ve ABD öncülüğünde bir dizi yaptırıma maruz kalması, ulusal çıkarları, ideolojik çıkarlarının önüne geçirmesine neden olmuştur. Nitekim uzun yıllardır üzerinde çalıştığ nükleer enerji alanında ve askeri silah ve teçhizat tedarikinde karşılaştığ sorunları aşmada Rusya, önemli bir partner olarak öne çıkmıştır. Ayrıca etnik ayrılıkçı hareketlerin kendi toprak bütünlüğü için de bir tehdit olduğunu düşünen İran, Çeçenistan'ın Rusya'dan bağımsızlığını kazanmak için verdiği mücadeleye mesafeli yaklaşmıştır. ${ }^{44}$ Çeçen lider Şamil Basiyev ise, İran'ın Çeçenistan sorununa ilişkin yaptı̆̆ 1 açıklamada İran'1 şu sözlerle eleştirmiştir:

“Imam Humeyni'nin size vasiyeti bu mudur? Sizi cihattan kim alıkoydu? Müslümanların katledilmesi niçin bir iç mesele olarak görülüyor? Eğer Çeçenistan Rusya'nın iç işleriyse, Iran neden ABD'nin iç işleriyle ilgili olmuyor? Iran Kafkasların ve Çeçenistan'ın en yakın komşusu. Allah nezdinde bu sizin göreviniz değil mi? İslam'a göre Cihada katılmak ve Müslümanları desteklemek gerekmiyor mu?". ${ }^{45}$

\footnotetext{
42 “Iran Report", RFE/RL 3, No. 6, (7 February 2000).

43 Martin Malek, "Russia, Iran and the Conflict in Chechnya, Caucasian Review of International Affairs 2, Say1. 1, (Winter 2008):25-34.

44 Samii, "Iran and Chechenya...".

45 "Iran Report”, RFE/RL.3 No. 28, (24 July 2000).
} 
Basayev'in eleştirdiği ve İslam dünyasının beklentilerinin aksi yönde hareket eden İran'ın Çeçenistan sorununa yaklaşımının arka planında, Rusya'yla ilişkilerin birçok açıdan göz ardı edilemeyecek derecede önemli olması yatmaktadır. Bunlardan birincisi, Rus savunma şirketleri İran'ın füze geliştirme programlarına doğrudan parça tedariki ya da teknik bilgi (know-how) vererek dolaylı yardımda bulunmaktadır. İkincisi, Rus şirketleri, Alman firmalarının yarıda bıraktığı Buşehr nükleer santralinin inşaatını devam ettirmektedir. Dolayısıyla Rus bilim adamları ve mühendisler İran'da çalışmaktadırlar ve İranlı bilim adamları ve mühendisler de, Rusya'da nükleer enerji alanında eğitim almaktadırlar. Üçüncü olarak Rusya, İran için en önemli silah tedarikçisidir. Rus yapımı T-72 tankları, zırhlı personel taşıyıcılar, kundağı motorlu toplar, çoklu roketatar sistemleri, Mig-29 ve Su-24 savaş uçakları ve küçük çaplı da olsa denizaltılar İran ordusu tarafindan kullanılmaktadır. ${ }^{46}$ Dördüncüsü ise Sovyetler Birliği'nin dağılmasının ardından İran'ın, Rusya'yı kendisine karşı bir tehdit ya da ideolojik bir rakip olarak görmemesidir. Bu bakış açısı Tahran yönetiminin dış politikadaki manevralarını kolaylaştıran bir faktör olarak öne çıkmaktadır. Nitekim Moskova ve Tahran yönetimleri, 1992-1997 yılları arasında devam eden Tacikistan'daki iç savaşın sona erdirilmesi için işbirliği dahi yapmışlardır. ${ }^{47}$

İki ülke arasındaki bu işbirliği Hatemi'nin, Eylül 2000'deki Birleşmiş Milletler (BM) toplantısı sırasında yaptığ “ “... Bizim Rusya'yla çok fazla ortak çıkarımız var... İnanıyorum ki iki ülke güçlü işbirliğini derinleştirecektir... Daha güçlü işbirliği her iki ülkeye de, dış güçlerin İran ve Rusya için yıkıcı sonuçlar elde etmek isteyen politikalarını boşa çıkarmasını sağlayacaktır" açıklamayla da net bir şekilde anlaşılmaktadır. ${ }^{48}$

Diğer taraftan İran'ın, Çeçenistan meselesini Rusya'nın iç sorunu olarak görmesinin arkasındaki diğer bir önemli neden ise, kendi toprakları içerisinde de çok sayıda etnik grubun yaşıyor olması ve bunların anayasa tarafından garanti altına alınacak dil ve kültürel taleplerinin olmasıdır. Zira İran sınırları içerisinde kuzeyde Azerilerin, batıda Kürtlerin, güneyde Arapların, güneydoğuda Belucilerin ve kuzeydoğuda Türkmenlerin varl1-

46 Islam, "The Nuclearization of Iran...", 266.

47 Nikolay Kozhanov, Understanding The Revitalization Of Russian-Iranian Relations", Carnegie Moscow Center, (May 2015), s. 8.

48 Islam, “The Nuclearization of Iran...”, 260-261. 
ğ1, Tahran yönetiminin “ayrılıkçı Çeçenistan'ın” zafer elde etmesi ve bu coğrafyadaki etnik grupları etkilemesinden endişe duymasının nedenini açıklamaktadır. Nitekim dönemin İran Dışişleri Bakanı Alirıza Ekberi, Rusya ziyareti sırasında Çeçenistan sorununa ilişkin yaptığı bir açıklamada, silahlı Çeçen liderler tarafından alevlendirilen ayrılıkçı düşüncelerin zafer kazanması durumunda bunun, bölgede adeta bir domino etkisi oluşturacağını ve bölge ülkelerinin toprak bütünlüğü için tehdit arz edeceğini belirtmiştir. ${ }^{49}$

\subsection{Dağlık Karabağ Meselesi}

Güney Kafkaslar, 1828 yılındaki Türkmençay Anlaşması'na kadar İran'ın (Pers İmparatorluğu'nun- o zamanki adıyla Kaçarlar Hanedanlığı) kontrolündeydi. Bundan dolayı 1990'ların başlarında İran'ın öncelikli hedefi, kuzey komşuları üzerindeki eski ticari, ekonomik, siyasi ve kültürel nüfuzunu geri kazanmaktı. Böylesi bir kazanım aynı zamanda uzun yıllardır bu coğrafyada rekabet içerisinde olduğu Türkiye ve belli ölçüde Rusya'ya karşı kazanım anlamına gelecekti. Ancak daha da önemlisi, bağımsızlığını yeni kazanan devletler İran'ın "İslam rejimi ihracı" politikasını hayata geçirebilmek için bir firsat sunmaktaydı. Zira Azerbaycan'ın, çoğunluğunu Şii Müslümanlar'ın oluşturduğu bir devlet olması Şii İslam inancını ihraç etmek/yaymak isteyen İran açısından uygun bir zemin oluşturmaktaydı.

Diğer taraftan İran topraklarında yaklaşık olarak 14 milyon civarında Azeri Türk'ün yaşaması ve dönemin Türkiye yanlısı, seküler, milliyetçi ve İran karşıtı karakteriyle öne çıkan Azerbaycan Cumhurbaşkanı Ebulfeyz Elçibey'in Azerileri tek bir çatı altında birleştirmeye dönük söylemleri, İran'ın Ermenistan'a yakınlaşmasına katkı sağlamıştır. Nitekim Elçibey birçok defa Azerbaycan'ın tekrar birleşeceğini, yani İran toprakları içerisinde yaşayan Azeri Türklerle bir devlet çatısı altında yaşayacaklarını ifade etmiştir. ${ }^{50}$ Ancak Sovyetler Birliği'nin dağılmasından sonra Dağlık Karabağ meselesi, Azerbaycan'la Ermenistan arasında bir savaşa dönüşmüş ve bu durum İran'1 doğrudan ilgilendiren bir hal almıştır.

49 Robert O. Freedman, "Russian-Iranian Relations in the 1990s", Rubin Center Research in International Affairs 4, Say1.2, (June 2000).

50 Dilip Hiro, “The Azerbaijan Question”, The Nation, (14 September 1992). 
25-26 Şubat 1992 tarihlerinde Karabağ Ermeni birlikleri yüzlerce Azeriye karş1 soykırım uygulayarak Azeri topraklarını işgal etmeye başlamıştır. ${ }^{51}$ Sorunun çözümü adına Nisan 1992 'de İran yönetimi arabuluculuk faaliyetlerini yoğunlaştırmış ve Azerbaycan Devlet Başkanı Vekili Yagub Memedov ile Ermenistan Devlet Başkanı Levon Ter-Petrosyan'1 Tahran'da bir araya getirmiştir. Bu çabalar sonucu 7 Mayıs 1992 tarihinde sekiz maddelik bir anlaşmaya varılsa da, bundan iki gün sonra Ermenistan ordusunun Şuşa'yı ve 17 Mayıs 1992 tarihinde de Laçin bölgesini işgal etmesi, İran'ın arabuluculuk çabalarının Azerbaycan tarafında kabul görmemesine neden olmuştur. Bu tarihten itibaren İran tarafından gelen arabuluculuk talepleri de, Bakü tarafından geri çevrilmiştir. ${ }^{52} 1993$ y1lı başlarında ise Mardakert ve Kelbecer'i ele geçiren Ermenistan, Ağustos ayına gelindiğinde İran s1nırına yakın olan Kubatlı, Cebrail ve Füzuli bölgelerini ele geçirmiştir. ${ }^{53}$

Karabağ sorununda aynı kampta yer alan Azerbaycan ve Türkiye ise, Ermenistan'la olan sınırlarını kapatmıştır. Gürcistan'ın da Türkiye ve Azerbaycan'la yakın bağları düşünüldügünde İran, Ermenistan için dünyayla kara bağlantısını sağlayan tek ülke olarak kalmıştır. Bu çerçevede İran Nisan 1992'de, savaşın en kızıştığı dönemde Ermenistan'a yakıt ve gıda desteği vermesinin yanında askeri üst düzey temsilciler de göndermiş ${ }^{54}$ ve Azerbaycan'in toprak kaybetmesine göz yumarak statükonun Azerbaycan aleyhine bozulmasına kayıtsız kalmıştır. ${ }^{55}$ Buna karşılık Ermenistan tarafının savaşı devam ettirebilmesi için gereken doğalgaz ve

51 Dağlık Karabağ meselesinin arka planı, iki tarafın mevcut probleme bakış açıları, tarafların askeri kapasiteleri ve çatışmaların başlamasından günümüze kadar olan süreç içerisinde hangi aşamalardan geçtiği, Ermenistan'ın saldırılarına karşı Azerbaycan'ın taarruzları ve ele geçirdiği yerler ya da daha sonra kaybettiği toprak parçaları gibi konular, bu çalışmanın kapsamını aştığı için burada ele alınmamaktadır. Mevcut çalışmanın odak noktası, İran'ın Dağlık Karabağ sorununa yaklaşımıdır. Bu nedenle Dağlık Karabağ meselesine dair çok yüzeysel bilgi verilmektedir.

52 Araz Aslanlı, "Karabağ Sorunu ve İran”, Tebriz Araştırmaları Enstitüsü, http://tebaren. org/wp-content/uploads/2016/06/\%C4\%B0ran-ve-Karaba\%C4\%9F-Sorunu.pdf, 21 Aralık 2018.

53 Svante E. Cornell, The Nagorno-Karabakh Conflict, Report no. 46, (Department of East European Studies, Uppsala University, 1999): 33.

54 Shaffer, “The Islamic Republic of Iran: Is It Really?”, 230.

55 Kendi ülkesindeki Azeri Türklerinin varlığını düşünen İran, toprak bütünlüğünü ve bağımsızlığını düşünerek hareket etmiş̧ir. Toplumsal yapıdaki farklılığı dikkate alan İran, her zaman parçalanma korkusuyla yaşamaktadır. 
yakıt ihtiyacını karşılamış, ${ }^{56}$ aynı zamanda gıda, hammadde ve enerji desteğine de devam etmiştir. ${ }^{57}$

Diğer taraftan Elçibey'in Haziran 1993'te devrilmesinin ardından iktidara gelen Haydar Aliyev, hem söylemlerinde hem de eylemlerinde İran karşıtlığından uzak durmaya çalışmıştır. Sadece İran'la değil, İslam dünyasıyla da ilişkilerini geliştirmeye özen gösteren Aliyev, Tahran ve Riyad'a resmi ziyaretlerde bulunmuştur. ${ }^{58}$ Ancak iki ülke arasında beklenen yakınlaşma bir türlü gerçekleşememiştir. Zira 1994 yılında Batılı petrol şirketlerinin liderliğinde imzalanan ve Bakü yönetimi tarafindan "yüzyılın anlaşması" olarak adlandırılan konsorsiyumda İran da \%5'lik payla yer almıştır. Fakat Nisan 1995 tarihinde ABD'nin Bakü'ye baskı yapması sonucu Aliyev yönetimi, İran'ı konsorsiyumdan çıkarmak zorunda kalmıştır. Bu nedenle İran yönetimi, Azerbaycan'1, "büyük Şeytan”'n oyuncağı olmakla suçlamış, Nahcivan'a sağladığı elektriği kesmiş ve ilişkiler tekrardan gergin seyrine geri dönmüştür. ${ }^{59}$

Nihayetinde Ermenistan (Ortodoks) Hıristiyanların çoğunlukta olduğu bir ülkedir. Yani dini açıdan bakıldığında, Şii İslam ile Hıristiyanlık arasında bir mücadele söz konusudur. Bundan dolayı hem Azerbaycan hem de İran topraklarında yaşayan Azeri Türkler, İran devletinin Azerbaycan'ın yanında saf tutmasını istemiştir. Fakat Tahran yönetiminin bu savaştaki genel tutumuna bakıldığında, Ermenistan yanlısı bir tavır net bir şekilde görülmektedir. Tahran yönetimi resmi olarak iki taraf arasındaki çatışmalarda tarafsız olduğunu ilan etmiştir. Ancak tarafsızlık ilanı, devletin resmi ideolojisinde belirtilen "dünyadaki Şiilerin koruyucusu ve savunucusu" söylemleriyle tutarsızlık içermektedir. Daha genel bir perspektiften bakıldığında ise İran'ın Azerbaycan Cumhuriyeti'nin çatışma içerisinde kalmasını veya bu durumun sürmesini neden tercih ettiği anlaşlabilir. Bu anlamda kaynaklarını sözkonusu savaşın/çatışmanın sürdürülmesi için harcayan

56 Çağaptay, ve Murinson, Good Relations between Azerbaijan and Israel...,; Suleymanov, ve Ditrych. "Iran and Azerbaijan...", 101-116; Gresh, "Coddling the Caucasus: Iran's Strategic Relationship...

57 Monmiquet ve Racimora, "The Armenia-Iran Relationship...”, 15-16; Suleymanov and Ditrych, "Iran and Azerbaijan...", 106-107.

58 Joseph A. Kechichian ve Theodore W. Karasik, "The Crisis in Azerbaijan: How Clans Influence the Politics of an emerging Republics”, Middle East Policy, (Summer 1996), :64-65.

59 "Iran Cuts Electricity to Nakhichevan" OMRI Daily Digest, (30 May 1995) 
Azerbaycan'ın, İran sınırları içerisinde yaşayan Azerilere daha az angaje olacağını ve onlar için cezbediciliğini kaybedeceğini düşünmektedir. ${ }^{60}$

Diğer taraftan Tahran yönetimi, Azerbaycan-Ermenistan Savaşı'nın İran topraklarına doğru büyük bir mülteci akınına neden olmasından ve kuzey sınırlarında istikrarsızlık ortaya çıkarmasından da endişe etmektedir. $\mathrm{Bu}$ nedenle Ermenistan'ın Dağlık Karabağ'da ilerlemesine bağlı olarak buradan kaçan Azerilerin İran tarafına geçmeye başlaması üzerine Tahran yönetimi, Azeri toprakları içerisinde 40 bin kişilik mülteci kampı kurmaya başlamıştır. ${ }^{61}$ Bunun arkasındaki ekonomik nedenlerin yanında en önemli bir diğer neden ise, İran topraklarına gelen Azerilerin, burada yaşayan soydaşlarıyla kaynaşıp bağımsızlık düşüncesini tetikleyebilecekleri olmuştur. İran Cumhurbaşkanı Haşimi Rafsancani'nin şu sözleri, bu yargıyı net bir şekilde ortaya koymaktadır:

"Uzun dönemde Azerbaycan milliyetçiliği, Komünist idaresindeki Moskova'nin da tecrübe ettiği gibi Tahran'daki İslam rejimi için uzun vadede sorun oluşturabilir. İslami bir rejime sahip olsun ya da olmasın, güçlü ve bağımsız bir Azerbaycan'ın ortaya çıkışı, İran içerisindeki Azeri milliyetçiliğini körükleyecektir" ".

Ancak, toprakları içerisinde bulunan Azeri nüfusun tepkisini çekmemek adına Ermenistan'a açıktan destek verdiğini ifade etmese de, İran, sadece Azeri azınlığın seslerini yükselttiği dönemlerde Ermenistan karşıtı söylemleri dolaşıma sokmuştur. ${ }^{63}$ İran'ın Karabağ meselesine dair bu yaklaşımı, Erivan yönetimi tarafından memnuniyetle karşılanmış ve Mayıs 1992'de İran'ın, Ermenistan, Azerbaycan ve Nahcivan sınırlarına gözlemci göndermesini talep etmiştir. Hatta çatışmanın üstünden on yıl geçmesine rağmen Ermenistan Dışişleri Bakanı Vartan Oskanian'ın Ekim 2002'de yaptığ açıklamada İran'ın Karabağ'ın istikrarının garantörü olduğunu söyleme$\mathrm{si}^{64}$, Ermenistan'la İran arasındaki ilişkinin mahiyeti noktasında ipuçları vermektedir. Nitekim Nisan 2003'te de Ermenistan Başbakanı Andranik

\footnotetext{
${ }^{60}$ Shaffer, "Iran's Role in the South Caucasus and Caspian Region...", 18-19.

${ }_{61}$ Cornell, The Nagorno-Karabakh Conflict, 88.

62 Cornell, The Nagorno-Karabakh Conflict, 89.

63 Shaffer, Iran's role...,19.

64 Mohammad Sadegh Yahyapour ve Mosayeb GharehBeygi, "Hegemonic Challenges of Iran and Russia in the Transcaucasia Region", Journal of Politics and Law 9, Say1. 5, (2016), : 295.
} 
Markaryan, İran'ın her zaman etkili duruşu sayesinde bölgede her zaman barış ve istikrarın koruyucusu olduğunu vurgulamıştır. ${ }^{65}$ İki ülke arasındaki yakınlaşma üst düzey karşılıklı ziyaretlerle de pekişmiştir. Mart 2002'de Erivan'ı ziyaret eden İran Savunma Bakanı General Ali Şamkani, Ermenistan Savunma Bakanı Serz Sarkisyan ile karşılıklı silah ticaretini de kapsayacak olan askeri işbirliğinin geliştirilmesi konusunda mutabakat zaptı imzalamışlardır. ${ }^{66}$

Yukarıdaki gelişmelerin haricinde İran, ABD öncülüğünde başlatılan yaptırımlar nedeniyle zor bir dönemden geçtiği bilinmektedir. Çünkü sadece ABD'nin kendisi değil, üçüncü ülkelere yaptığı baskılar neticesinde söz konusu devletler de İran'a yatırım yapmaktan veya işbirliği içerisine girmekten kaçınmaktaydı. Bundan dolayı hem bölgedeki yalnızlığını gidermek, hem de ABD'de etkin olan Ermeni lobisinin desteğini alabilmek, İran açısından önem arz etmekteydi. Bu anlamda Ermenistan'la İran, birbirini izolasyondan kurtarmanın bir aracı olarak görmekteydiler. ${ }^{67}$ Ancak netice itibariyle bu işbirliğinden en fazla faydalanan tarafin Ermenistan olduğunu söylemek mümkündür. Zira Ermenistan, Azerbaycan'la Dağlık Karabağ yüzünden savaştığı dönemlerde İran'dan hem askeri, hem de ekonomik destek alarak savaşı sürdürebilmiş ve üstünlük kurabilmiştir. ${ }^{68}$ Ancak İran, ABD'nin yaptırımlarına tabi olmaktan kurtulamamış ya da söz konusu yaptırımların hafifletilmesi gibi bir durum ortaya çıkmamıştır.

\section{Sonuç}

90'lı y1llarda Rafsancani ve Hatemi gibi iki 1lımlı liderin (lider faktörü) İran'da iktidarda olması, ülkede Humeyni liderliğinde tesis edilen Şii-İslamcı siyasal kültürün değiştiği anlamına gelmemektedir. Zira

65 Hatem Cabbarlı, "Ermenistan'ın İran Politikası”, Çankırı Karatekin Üniversitesi Uluslararası Avrasya Strateji Dergisi 10, Sayı. 10: 155-159.

${ }^{66}$ Ze'ev Wolfson, Armenian "Traces" in the Proliferation of Russian Weapons in Iran, ACPR Policy Paper No. 143. (2009): 10.

67 Julien Zarifian, "Iran and Its Two Neighbours Armenia and Azerbaijan: Resuming Relationships under America's Suspicious Eyes", Iran \& the Caucasus 13, Say1. 2, (2009): 387.

68 Burada, Ermenistan'ın İran'dan aldığı desteğin Dağlık Karabağ savaşında üstün olmasının tek nedeni olduğu savunulmamaktadır. Zira Rusya'dan almış olduğu askeri yardım, söz konusu üstünlüğün en belirgin göstergesidir. 
Humeyni'den sonra Dini Lider olan Ali Hamaney de, benzer görüşleri dile getirerek, İran'ın, İslam ümmetinin haklarını savunduğunu, Şii İran'ın, gerçek İslam anlayışını yansıttığını ve yakın coğrafyasında da bu anlayışın yayılması gerektiğini savunmuştur. Bu bağlamda Tahran yönetiminin, komşu devletlerdeki Şii halkları destekleyerek kendi etki alanını genişletmesi beklenmiştir. Buradan hareketle 1979 Devrimiyle birlikte İran, Şiilik temelli İslami birlikteliği öngören evrensel bir konsept üzerinden hareket etmek istemiştir. Aynı zamanda dış politika da, teorik olarak İslam düşüncesi etrafında şekillenmiştir. Bunların yanında Sovyetler Birliği’nin dağılmasının ardından Müslüman nüfusa sahip devletlerin bağımsızlıklarını kazanması da, İran'ın, Şii İslam'ı ihraç etme politikası ve İslam dayanışması$\mathrm{n}$ ' göstermesi açısından muazzam firsatlar sunuştur. Bu firsatların yanında ise, çok etnikli bir yapıya sahip olan İran açısından bir takım tehditlerin de beraberinde geldiğini ifade etmek gerekir.

İran, söz konusu dinamikler üzerinden Pakistan'da Şii nüfusun yoğun olduğu bölgelerle; Lübnan'daki Şiilerle veya Yemen'deki Husilerle ilişkilerini geliştirerek Suudi Arabistan-Pakistan işbirliği örneğinde olduğu gibi rakip olarak gördügü ülkelere karşı kendisine pozisyon üretebilen bir aktör olarak öne çıkmayı başarmıştır. Ancak Irak-İran Savaşı ve sonrasında yaşanan ekonomik ve siyasi sıkıntılar, Tahran yönetiminin dış politikasını, ideolojik perspektiften ulusal çıkarların öncelikli olarak gözetildiği pragmatist bir düzleme kaydırmıştır.

Humeyni sonrasında iktidara gelen Rafsancani ve Hatemi, Irak'la savaş ve ABD yaptırımları nedeniyle ekonomik ve siyasi olarak zor bir süreçten geçen İran'1 refaha kavuşturmak adına, yumuşama "detente" ve Medeniyetler Arası Diyalog "Dialogue Among Civilisations" politikalarını uygulamaya gayret göstermişlerdir. Bu nedenle Humeyni’nin sınırlarını çizdiği ideolojik ve yakın çevreye müdahaleci revizyonist yaklaşım, yerini çıkarların öncelendiği, işbirliği ile denge arayışlarını öne çıkartan bir anlayışla yer değiştirmiştir.

Söz konusu değişim nedeniyle Çeçenistan ve Dağlık Karabağ örneklerinde olduğu gibi ideolojik beklentilerin aksine reel politik kaygılar ekseninde hareket edildiği görülmektedir. Clement Therme'nin de vurguladığı üzere Tahran yönetiminin Rusya ile ekonomik ve stratejik işbirliği nedeniyle İslam kardeşliği/birlikteliği anlayışını arka plana atması, İran'ın dış poli- 
tikasında ideolojinin ana belirleyici unsur olmadığını göstermiştir. ${ }^{69}$ Ayrıca Azerbaycan'ın Türkiye'yle ve ABD başta olmak üzere Batılı ülkelerle yakın işbirliği içerisinde olması, ABD'yi “büyük şeytan” ve İsrail'i de "küçük şeytan" olarak tanımlayan İran rejimi tarafından endişeyle karşılanmıştır. Buna Azerbaycan'ın din kimliğinden ziyade etnik, yani Türklük kimliğine vurgu yapması da eklenince, İran Azerbaycan'a mesafeli bir dış politika tercihinde bulunmuştur. Elçibey döneminde Azerbaycan'ın, Humeyni tarafindan İran'da tesis edilen İslam modelini reddetmesi de bu görüşü desteklemektedir.

Diğer taraftan ABD öncülüğünde İran'a karşı başlatılan ve birçok ülke tarafindan da desteklenen ekonomik, siyasi, askeri ve teknolojik yaptırımlar, İran ekonomisini zora sokmaktadır. Bu kötü şartların yanında Batı dünyasıyla yakın ilişkilere ve zengin yer altı kaynaklarına sahip Azerbaycan'ın güçlenmesi, İran sınırları içerisinde yaşayan Azeriler için de bir cazibe oluşturacağı düşünülmektedir. Bu nedenle çok etnikli bir yapıya sahip olan İran, hem Azerbaycan'ın güçlenmesini istememektedir, hem de bu çok etnikli yapısından kaynaklanabilecek ayrılıkçı hareketlerin önüne geçmeyi hedeflemektedir. Bu noktada Humeyni'nin İranlı karar vericilere yol gösteren söylemleri ile devletin ulusal çıkar kaygıları arasında bir çatışma ortaya çıkmaktadır. Bu nedenle İran'ın dış politika hamlelerine bakıldığında, kurmuş olduğu ittifaklarda veya işbirliklerinde İslami kimliğin nadiren etkili olduğu, bunun yerine pragmatist davranışların öne çıktığı görülmektedir. Dolayısıyla Şii İslamcı siyasal kültürün, ulusal çıkar kavramı altında retorik düzeyde kullanılan bir araç görüntüsüne indirgendiği anlaşılmaktadır.

\section{Kaynakça}

Ahin, Tahereh, "İran İslam Cumhuriyeti'nde Devlet Yapısı", Amme İdaresi Dergisi 43, Say1. 2, (2010), 81-100.

Akhavi, Shahrough, Religion and Politics in Contemporary Iran, Albany State University of New York Press, ch. 5. 1980.

Algar, Hamid, İslam Devrimi'nin Kökleri, çev., M. Çetin Demirhan, İşaret Yayınları, Ankara, 1988.

69 Clement Therme, "Tehran and the Chechen Question. Caucaz.com", 26 September 2006, http://www.caucaz.com/home_eng/breve_contenu_imprim.php?id=262 (Erişim Tarihi: 13 Ocak 2019). 
Algar, Hamid (Ed.), Islam and Revolution: Writings and Declarations of Imam Khomeini, Berkeley: Mizan Press, 1981.

Amuzegar, Jahangir, The Dynamic of the Iranian Revolution, The Pahlavis' Triumph and Tragedy, New York: State University of New York Press, 1991.

Breuning, Marijke, Foreign Policy Analysis: A Comparative Introduction, Palgrave Macmillan, New York, (2007).

Cabbarlı, Hatem, “Ermenistan'ın İran Politikası”, Çankırı Karatekin Üniversitesi Uluslararas1 Avrasya Strateji Dergisi 10, Sayı. 10, 147-174.

Clawson, Patrick, "The Khatami Paradox", içinde Iran Under Khatamı A Political, Economic, And Military Assessment, ,(Eds.) Patrick Clawson et. al., 1-13, The Washington Institute For Neear East Policy, (1998).

Cornell, Svante E., The Nagorno-Karabakh Conflict, Report no. 46, Department of East European Studies, Uppsala University, 1993.

Çağaptay, Soner, ve Alexander Murinson, Good Relations between Azerbaijan and Israel: A Model for Other Muslim States in Eurasia? Washington: The Washington Institute for Near East Policy Press, 2005.

Çitlioğlu, Ercan, İran'1 Anlamak, Başkent Üniversitesi,_2015.

Darwich, May, "The Ontological (In)security of Similarity: Wahhabism Versus Islamsm in Saudi Foreign Policy", Institute of Middle EastStudies, GIGA Work Papers, No. 263, (2014), 1-26.

Farsoun, Samih K. and MASHAYEKHI Mehrdad, içinde "Introduction: Iran's Political Culture", Iran, Political Culture in the Islamic Republic, (Ed.)Samih K. Farsoun and Mehrdad Mashayekhi, Routledge, New York, 1993.

Ferrero, Mario, The Rise and Demise of Theocracy: Theory and Some Evidence, "Religion and Democracy" in the annual conference of the Association for Public Economic Theory, Galway, (2009), June 17-20.

Freedman, Robert O., "Russian-Iranian Relations in the 1990s", Rubin Center Research in International Affairs 4, No.2, June (2000).

Gölpınarl, Abdülbaki, Tarih Boyunca İslam Mezhepleri ve Şiilik, Der Yayınları, İstanbul, 1997. 
Gresh, Geoffrey, "Coddling the Caucasus: Iran's Strategic Relationship with Azerbaijan and Armenia", Caucasian Review of International Affairs 1, Kış (2006).

Higley, John and Michael Burton 'The Elite Variable in Democratic Transitions and Breakdowns. 'American Sociological Review 54, (1989):17-32. Hiro, Dilip, "The Azerbaijan Question”, The Nation, 14 September (1992). Humeyni, İmam, İslamda Devlet, İstanbul: Objektif Yayınları, 1991.

Islam, Thowhidul, "The Nuclearization of Iran and the Policy of Russia”, Asian and African Studies 22, Say1. 2, (2013), 248-278.

Jahanbakhsh, Forough, Islam, Democracy And Religlous Modernism In Iran (1953-1997): From Bàzargan To Soroush, PhD Thesis, Institute of Islamic Studies, McGill University, Montreal, Temmuz, 1997.

Kechichian, Joseph A. ve Theodore W. Karasik, "The Crisis in Azerbaijan: How Clans Influence the Politics of an Emerging Republics", Middle East Policy, Summer, (1996), 57-71.

Kozhanov, Nikolay, Understanding The Revitalization Of Russian-Iranian Relations", Carnegie Moscow Center, (May,2015).

Krauthammer, Charles, "The Unipolar Movement Revisited", The National Interest 3, Winter, (2002), 25-26.

Malek, Martin, "Russia, Iran and the Conflict in Chechnya, Caucasian Review of International Affairs 2, Say1. 1, Winter (2008), 25-34.

Monmiquet, Claude ve William Racimora, "The Armenia-Iran Relationship, Strategic Implication for Security in the South Caucasus Region", European Strategic Intelligence \& Security Center, (17 January 2013).

Muller, Edward and Mitchell Seligson 'Civil Culture and Democracy: The Question of Causal Relationships', American Political Science Review 88, (1994): 634-652.

Onat, Hasan, "İan İslam Devrimi ve Şiilik", Mezhep Araştırmaları 2, (Güz 2013), 236.

Onat, Hasan, "Şiilik ve Günümüz Şiiliğinde Bazı Yeni Yaklaşımlar", İslami Araştırmalar 3, Sayı. 3, (Temmuz 1989),122-138. 
Ramakrıshnan, Ak, [The Making of A Revolution I: Religious PoIitical Discourse, Chapter 3, 2010.

Saatchi, Autoosa Elizabeth Kojoori, The Culture of Revolution: Revolutionary Transformation in Iran, University of Nevada, 2010.

Samii, A. William, "Iran and Chechenya: Realpolitik at Work", Middle EAst Policy Council 8, Say1. 1, (Spring 2001).

Sanal, Enes, "Demokrasi Kavramı Açısından Devlet ve Din İlişkileri", Başkent Üniversitesi Stratejik Araştırmalar Merkezi, Ankara, (2014), 1-8.

Shaffer, Brenda, "Iran's Role in the South Caucasus and Caspian Region: Diverging Views of the U.S. and Europe", içinde Iran and Its Neighbors: Diverging Views on a Strategic Region. ran and Its Neighbors: Diverging Views on a Strategic Region, Eugene Whitlock (Ed.), Berlin: SWP, (July 2003).

Shaffer Brenda, "The Islamic Republic of Iran: Is It Really?", Brenda Shaffer (Ed.), The Limits of Culture, Islam and Foreign Policy, Cambridge: The MIT Press, (2005).

Sinkaya, Bayram, "İran İslam Cumhuriyeti'nde Siyasal Yap1 ve Yönetim", , Ortadoğu Siyasetinde Iran, Turel Yılmaz ve Mehmet Şahin (Ed.), Ankara: Barış Kitabevi, (2011).

Suleymanov, Emil, ve Ondrej Ditrych. "Iran and Azerbaijan: A Contested Neighborhood", Middle East Policy 14, Say1 2, (2007), 101-116.

Tabriz, Asghar Alam, Aydinlartn, Dini Liderler ve Esnafin Iran'in Yakın Dönem Toplumsal Hareketlerindeki ve Devrimlerindeki Rollerinin Incelenmesi, Yayınlanmamış Doktora Tezi, Ankara: Ankara Üniversitesi, 2004.

Taflıŏlu, M. Serkan, İran İslam Cumhuriyeti'nde Egemenlik ve Meşrûiyet Kaynağ1 "Velâyet-İ Fakih" Ankara Üniversitesi SBF Dergisi 68, No. 3, (2013), 97-100.

Taflıoğlu, M.Serkan, Şah Nasil Mat Oldu, Kripto Yayınları, 2010.

Wastnidge Edward, "The modalities of Iranian soft power: from cultural diplomacy to soft war", Politics35, Say1. 3-4, (2015), 364-377.

Wolfson, Ze'ev, Armenian "Traces" in the Proliferation of Russian Weapons in Iran, ACPR Policy Paper No. 143, (2009), 1-17. 
Yahyapour, Mohammad Sadegh ve Mosayeb GharehBeygi, "Hegemonic Challenges of Iran and Russia in the Transcaucasia Region", Journal of Politics and Law 9, Sayı. 5, (2016).

Yeğin, Abdullah, "Devrim'in 35. Yılında İran Dış Politikası", SETA Perspektif, Say1. 32, (2014).

Zarıfian, Julien, "Iran and Its Two Neighbours Armenia and Azerbaijan: Resuming Relationships under America's Suspicious Eyes", Iran \& the Caucasus 13, No. 2, (2009), s. 383-399.

"Iran Cuts Electricity to Nakhichevan", OMRI Daily Digest, (30 May 1995) “İran İslam Cumhuriyeti'nde Anayasal Sistem ve Siyasi Partiler, Orsam Rapor no. 112, (Mart 2012), 6.

"Iran Report", RFE/RL 2, No. 39, (4 October 1999),

"Iran Report", RFE/RL 3, No. 6, (7 February 2000).

"Iran Report", RFE/RL 3, No. 12, (20 March 2000).

"Iran Report", RFE/RL 3, No 28, (24 July 2000).

\section{Internet Kaynakları}

"The Seventh Islamic Summit Conference (Session of Fraternity and Revival). Casablanca, Kingdom Of Morocco", 11-13 Rajab 1415h (13-15 December, 1994), http://www.oic-oci.org/english/conf/is/7/7th-is-summit. htm\#FINAL\%20COMMUNIQUE (accessed 25 February 2007

Aslanl1, Araz, "Karabağ Sorunu ve İran", Tebriz Araştırmaları Enstitüsü, http://tebaren.org/wp-content/uploads/2016/06/\%C4\%B0ran-veKaraba\%C4\%9F-Sorunu.pdf, (Erişim Tarihi: 21 Aralık 2018).

Therme, Clement, "Tehran and the Chechen Question. Caucaz.com", 26 September 2006, http://www.caucaz.com/home_eng/breve_contenu_imprim.php?id=262 (accessed 13 January 2019). 